\title{
Outdoor Lighting Design Teaching Exploration with Creative Thinking as Its Core
}

\author{
Liu Xiaoxi ${ }^{1, \mathrm{a}, \mathrm{b}}$, Chen Yansong ${ }^{2}$ and Zhang Xinyue ${ }^{1}$ \\ ${ }^{1}$ Faculty of Arts, Communication University of China, 100024, Beijing, China \\ ${ }^{2}$ Neuroscience and Intelligent Media Institute, Communication University of China, 100024,Beijing, China
}

\begin{abstract}
Creative thinking is the ability to think creatively. It is of great guidance for the development of lighting design major to combine the spirit of innovation and the advantage of creativity when designing. Based on intention extraction, space reconstruction, environmental narrative and system construction, this paper, integrating creative thinking construction into the task of the "Four Orders of Design" in outdoor lighting design, aims to help lighting design majors to form creative thinking and make an organic whole of technology and art in lighting design projects.
\end{abstract}

\section{The significance of creative thinking in lighting design teaching}

In modern society, lighting design, being a rising branch of professional design, corelates with several other fields and practice of this industry including architectural design, environmental art design, public art design. While integrating culture, art, environment, and technique, lighting design needs not only to satisfy public functional requirement of nighttime activities but also people's yearning for a better life. By sorting out the tendency and demand of lighting design market, one can easily find the strengthening epochal feature and increasing influence of lighting design. Light elements start to appear at urban space by means of interactive installation and media architecture. Therefore, it has become top priorities in lighting design teaching to incorporate concerning design concept and creative thinking into design of lighting environment and foster professionals with solid theoretical foundation and innovative design abilities.

Generally speaking, creative thinking is one of the primary drivers of design improvement and technological change ${ }^{[1]}$. For one thing, creative thinking of lighting design includes thinking through imagination, spatial thinking, logical thinking and systematic thinking. For another, it also absorbs the essence of art philosophy, artistic aesthetics, and art psychology. This paper holds that the process of lighting design shows a strong link of technique and art, which turns the production-centered design activity into solution-centered design activity. As a result, lighting design provides solution to complicated connection, which embodies in a variety of aspects such as innovation of design concept, regeneration development of nightscape, development of night economy, promotion of public participation and cultural communication. In David Kelley's opinion, the core aim

\footnotetext{
* Corresponding author: ${ }^{\mathrm{a}}$ 1xxcici@163.com
}

of design education is to bring out the full creative potential in every student and make them feel delightful in creation through constant design training. Gradually their creativities will be strengthened and finally they themselves will gain creative confidence ${ }^{[2]}$. Therefore, the focal point and difficulty of this course is to foster creative thinking. We chose to explore practice design projects with openness, to guide students to incorporate creative thinking in the "Four Orders of Design" of lighting design. In this way we expect to systematically integrate technique and art, and finally solve the problem of complexity in designing.

\section{Exploration of curriculum design}

The main theoretical knowledge of this course focused on the principle and method of outdoor lighting design along with its aesthetic presentation and art performance. On the practice part, taking the internal balance and coordination of the course into consideration, students were divided into several groups to fulfil the design task. The practice phase of this course adopted open proposition. With the design task being outdoor lighting design of "Baitasi Remade (the revival of the White Pagoda Temple)", students could choose any area of Baitasi (the White Pagoda Temple) historical and cultural preservation zone to perform their design. It is significant to impart the basic theoretical knowledge of outdoor lighting design to students. After that, this course endeavoured to foster students' creative thinking into each step of outdoor lighting design and lead them to apply multiple lighting elements and lighting medium in their practical project. Thus, the ultimate evaluation criteria of this course were not confined to the presentation of the design but the manifestation of creative thinking. It is required students to actively 
develop their thinking during the whole process, to take comprehensive consideration of environmental benefits, economic benefits and social benefit, and finally to reflect the kind of creative thinking with culture uniqueness and communication feature in their design task.

During the practice teaching part, the author also tried to organize the curriculum in the form of cooperative education with Folk Games, an undergraduate course from School of Animation and Digital Arts. Cooperative education holds the advantage to broaden the designing horizon and foster creative thinking for students from both courses. That especially helped lighting design majors to improve their abilities on the level of design "Activities" and "System". During the process of collaborative teaching, students from different professional background were grouped together and work collaboratively, in which way students from folk games course could also design their games creatively in different environment of urban space.
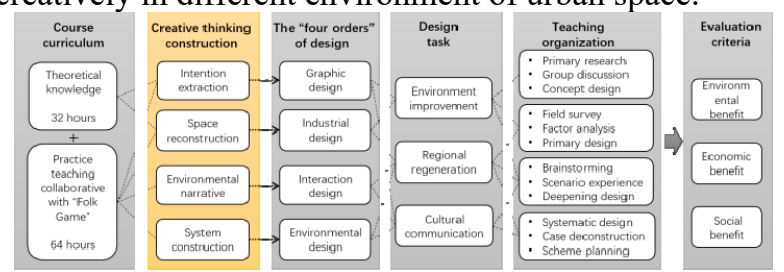

Figure 1. The curriculum design of outdoor lighting design with creative thinking as its core (created by the author)

\section{The teaching practice with frame of creative thinking as its core}

Lighting design has appeared and developed with people's constant pursuit of a better life. While crossintegrating with other fields of art, the connotation of lighting design is also enriched by its utility function and creative thinking. The main task of outdoor lighting design involves a whole process which unifies lighting elements application on physical level, concept efficient expression on presenting level, ensuring service experience on phycological level, combining public participation and smart technique on interacting level, as well as social culture and economy development on communication level.

"Four Orders of Design" means to categorize design projects into four layers: graphic design by using symbols and characters; industrial design by studying a physical object; interaction design by focusing on how human beings relate to other human beings through the mediating influence of products; and environmental design by organizing a system or environment ${ }^{[3]}$. "Four Orders of Design" begins to guide outdoor lighting design moving forward to a more mature direction when the practice task of the collaborative course develops from "tangible artifact" design activity to the balance of more complicated relations. However, to introduce creative thinking into the whole teaching process of this course, it needs to connect "Four Orders of Design" with creative thinking, and help students gradually transform from "primary design" to "secondary design".

\subsection{Intention extraction based on imaginary thinking}

After receiving the design task in the practice teaching part, students were asked to make background analysis, primary research and data integration to determine design area in accordance with the design task. During this process, creative thinking required students to, extending from thinking through imagination, create a new image through synthetic representation, analogy association, graphic externalization and symbols extension.

To be specific, students need analyze the spatial type of the selected area under the training of "intention extraction", extending the fundamental theories of outdoor lighting design to constructing different object spaces according to place, path and area, the three properties of the space ${ }^{[4]}$, exploring comprehensively the expressions of different spaces, and finally abstracting the internal association. For instance, the design objects of figure 2, the street space, which belongs to path property, required students to focus more on small-scale scenes and linear symbols in extracting and analyzing intentions.

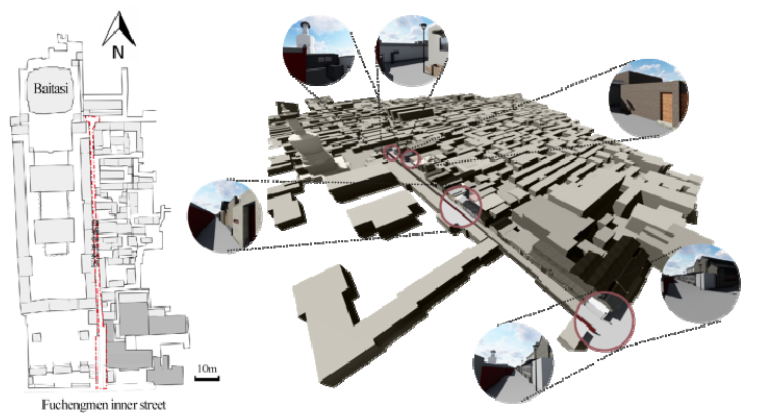

Figure 2. Analysis of design scheme of street space in selected topics (students' assignment)

"Intention extraction" is on the premise of taking prerequisite theoretical course. Initiating from the "origin" of design, it enables creative thinking to function on the dimension of performance by means of thinking through imagination and to explore the symbolic expressions using light as medium based on different space properties. This process is part of the initial design in teaching practice, therefore the overt and covert design factors are mixed, which is likely to lead to the vagueness of intention extraction and leaves much more creating space for the next step of design.

\subsection{Spatial restructure based on spatial thinking}

After establishing the design intention of outdoor lighting environment, students are needed to study the background information and material of the design objects elaborately and conduct in-depth researches on field survey. In this process, on the one hand, spatial thinking of creative thinking demanded students to systematically master the modification of space and the insertion and transfixion of dimensional interface. On the other hand, it required students to think comprehensively 
of the relations between object, human and space in design.

To put it in a more elaborate way, students needed to study the "tangible artifact" with its subjective elements (including the characteristics, visual aesthetics, physiology and psychology, main behavior patterns and relevant culture) and objective elements (including the geographical, climate, time and space environment features of site, relevant norms of the design, the latest technological innovations, era and economic background, sustainable development of design and communication of information etc.) in the design object, under the premise of constantly demonstrating and adjusting the physical dimension and performance dimension of the design.

The process of "spatial reconstruction" centers on human experience of the psychological dimension of lighting design, gradually representing the design intention in the reconstructed space by means of light elements. As shown in Figure 3, the quantitative design of light was expressed from the macro perspective through the research on spatial planning, analysis of the characteristics of visual horizon, investigation of the trend of crowd flow, contemplating lighting environment between object and space, human and space, space and space.
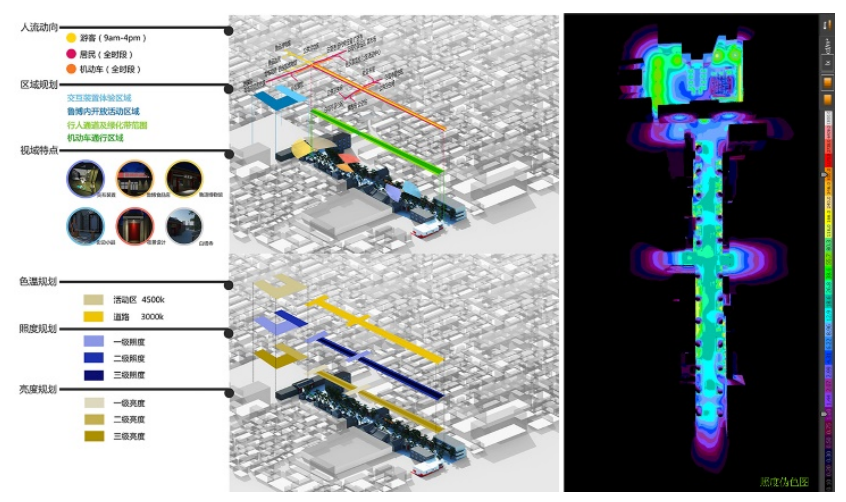

Figure 3. Space lighting design determined by analyzing subjective and objective elements (students' assignment)

\subsection{Environmental narrative based on divergent thinking}

After exploring the preliminary expression of "tangible artifact" in the design project, students have to think about the design of environmental narrative by divergent thinking. Environmental narrative asks students to master the basic regulations and rules of narrative, and moreover, to take objective realities into consideration. The existing theoretical knowledge and technologies of interactive design should be integrated into the artistic expression of outdoor lighting design by divergent thinking training. It could help students organize activities and events which can enhance experience, intensify emotion and build space narrative logic in their design projects.

This design process, driven by public participation on interaction level in lighting design, has creative thinking, in its divergent form, function on interaction design and focuses on interaction strategy and interaction means from the perspective of space narrative. Combing with the collaborative teaching of Folk Games, the lack of interactive technique could be compensated by the lighting design majors, and more lighting-centered artistic expression on visual presentation could be complemented by game design majors in the meantime. When creating activities and incidents of environmental narrative in divergent thinking, all types of "dynamic lighting" design, be it media architecture design on urban scale or dynamic lighting scene on street and space scale, as influential factors for visual cognition, should be analyzed thoroughly to be able to establish safe and friendly interacting experience in different environment ${ }^{[5]}$. This process significantly affects the quality and sensation of outdoor lighting environment. As can be seen in figure 4, by divergent thinking, students, taking the differences of subjects' age and gender into consideration, simulated specific "activities and incidents" in this chosen area. To establish safe and friendly interacting experience, the visual cognition effects should be analysed. And finally, the specific "object" and lighting elements for environmental narrative are designed.

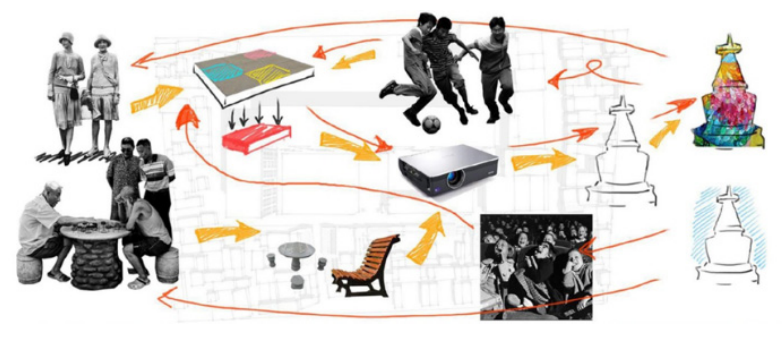

Figure 4. Activities and incidents of lighting design caused by divergent thinking (students' assignment)

\subsection{System construction based on systematic thinking}

During teaching practice of outdoor lighting design, besides the graphic design of intention extraction, industrial design of tangible artifact, interaction design of environmental narrative, the fourth layers of "four orders of design", environmental design by organizing a system should also be paid more attention. Moreover, creative thinking, in the form of systematic thinking, guides us to ponder over communication elements including senders, receivers, channels, information, cultural codes and theme in a comprehensive way. Also, it leads us to apply innovative idea and communication theory in outdoor lighting design from environmental level, by which design strategy will be upgraded to a systematic level. And by means of integration and deduction, creative thinking and design will permeate itself with corresponding cultural background and spirit of time.

In the process of collaborative teaching, creative thinking, guided by "system construction", not only connected the artistry and technology beyond human being's production, life, work and entertainment, but 
also integrated several technological theories including multimedia technology, interaction technology and game technology into lighting design methodologies. In that way, Baitasi historical and cultural preservation zone was redesigned and the traditional culture was revitalized. Specifically speaking, after deeply delving the traditional regional culture of Baitasi area, students analyzed the connection between the environmental feature and interrelationship among human (substance) and environment. Given all those, to systematic perform creative outdoor lighting design from the communication perspective, the most environmental-suitable and communication-free design scheme was finally generated with traditional culture and folk games as the core of creative thinking.
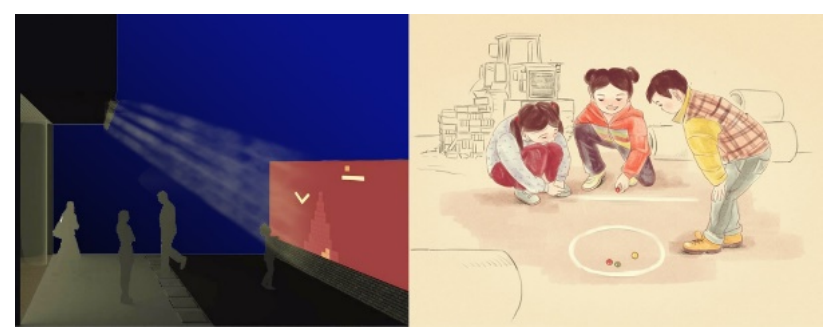

a. Baita and Pinball

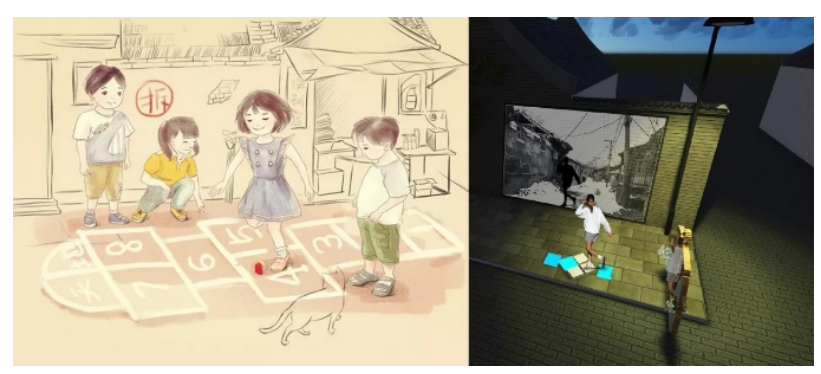

b. Passing Luxun and Baita

Figure 5. Outdoor lighting design based on the creative strategy of traditional folk games (students' assignment)

Professor Amos Rapoport stated that environment holds meaning as part of a cultural system of symbols and influences our actions and our determinations of social order ${ }^{[6]}$. Environment is a non-verbal system and channel that allows designer and receiver to communicate between human and environment. The design of outdoor lighting environment in this layer aimed at realizing culture continuity, enables creative thinking function as systematic thinking on the dissemination of design. By deeply delving the connection between human(substance) and environment, human(substance) and local culture, this process enhances the interaction and entertainment of spatial experience, and to some extent, promote traditional folk culture to the modern world. As shown in fig.5a, traditional pinball game is the prototype of this creative design. Students used the red wall of Baitasi as the medium of motion-sensing game, borrowing the rules and strategy of playing traditional pinball game to invent a game named "Baita and Pinball". Fig.5b was a creative design, the game of Passing Luxun and Baita, prototyped on traditional hopscotch, using weight-sensing lighting tiles and interactive projection as medium and borrowing the form of hopscotch, bringing more folk elements and traditional culture for this historical and cultural preservation zone, meanwhile systematically associating the Luxun Museum with Baitasi.

\section{Conclusion}

Creative thinking construction in outdoor lighting environment is a process that starts from the "primary design" and continually develops towards the "secondary design". Besides, this teaching exploration with creative thinking construction as its core also complements the awkward situation of design education that "what we neglect, the value of exploration, experiment, insolubility and possibility, is exactly what may improve education quality and foster creativity" in China ${ }^{[7]}$. This course has injected traditional curriculum gene of Communication University of China into outdoor lighting design course. Students were encouraged to break the limit of their own major in practice, and they also integrated creative design thinking into each layer of the "Four Orders" of outdoor lighting design. By deconstructing and reconstructing, students performed lighting design on Baitasi historical and cultural preservation zone in an artistic, comfortable, and interactive way, which represented the cross-disciplinary and cross-medium feature of lighting design and its epochal influence.

\section{Acknowledgment}

This paper was funded by the project (51508301) of Natural Science Foundation of China, and was funded by Science and Technology Plans of Ministry of Housing and Urban-Rural Development of the People's Republic of China, and Opening Projects of Beijing Advanced Innovation Center for Future Urban Design, Beijing University of Civil Engineering and Architecture (UDC2017020312)

\section{References}

1. E. B. N. Sanders, P. J. Stappers, Co-design, 4(1), 518 (2008)

2. Q. Dai, W. Yang, B. Zhang, New Architecture, 2, 112-115 (2012)

3. R. Buchanan, Design issues, 17(4), 3-23 (2001)

4. W. Zhu, Space, Symbol, City: A Design Theory of City (China Architecture \& Building Press, Beijing, 1993)

5. X. Liu, Zhuangshi Journal, 3, 101-103 (2016).

6. R. Amos, The Meaning of the Built Environment: A Nonverbal Communication Approach (University of Arizona Press, 1990)

7. L. Wu, Journal of Nanjing Arts Institute (Fine Arts \& Design),2, 5-9(2014) 